
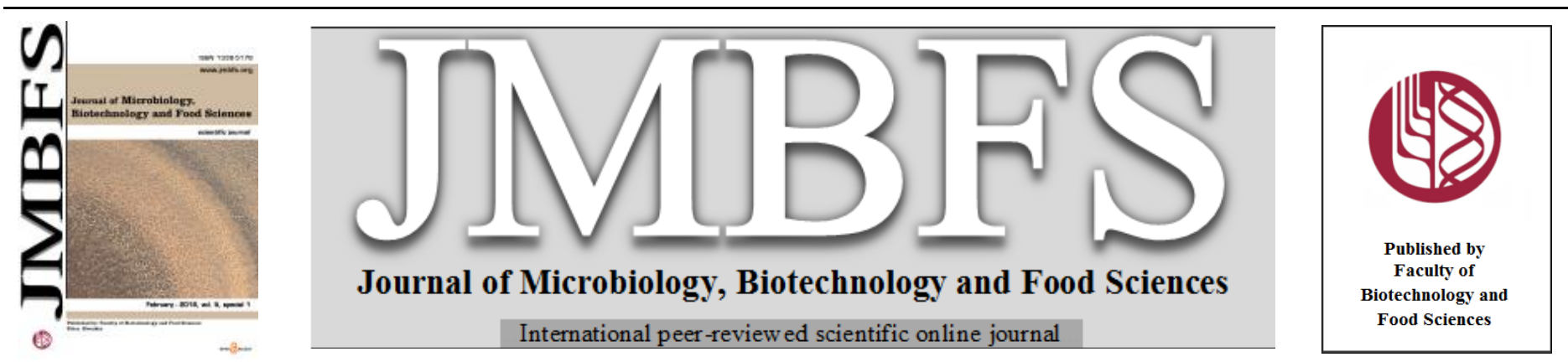

\title{
ASSESSMENT OF SELECTED ANTIOXIDANT PARAMETERS IN RABBIT BLOOD EXPOSED TO EPICATECHIN IN VIVO - FOUR WEEKS EXPOSURE
}

\author{
Katarina Zbynovska* ${ }^{l}$, Anna Kalafova ${ }^{l}$, Lubomir Ondruska ${ }^{2}$, Rastislav Jurcik ${ }^{2}$, Lubica Chrastinova ${ }^{2}$, Marcela Capcarova $^{l}$ \\ Address(es): MSc. Katarina Zbynovska, \\ ${ }^{1}$ Department of Animal Physiology, Faculty of Biotechnology and Food Sciences, Slovak University of Agriculture in Nitra, Tr. A. Hlinku 2 , 94976 Nitra, Slovak \\ Republic, Phone number: +421376414287 \\ ${ }^{2}$ Animal Production Research Centre Nitra, Hlohovecka 2, 94901 Nitra, Slovak Republic.
}

*Corresponding author: zbynovska.katarina@gmail.com

doi: 10.15414/jmbfs.2016.5.special1.7-9

\section{ARTICLE INFO}

Received 16. 12. 2015

Revised 21. 1. 2016

Accepted 26. 1. 2016

Published 8. 2. 2016

Regular article

open $\partial_{\text {Access }}$

\begin{abstract}
The aim of present study was to analyse selected antioxidant parameters in blood of rabbits after epicatechin administration during four weeks. Animals (adult female rabbits, body weight $4 \pm 0.5 \mathrm{~kg}$ ) were divided into four groups: control group (C) and experimental groups (E1 - E3). Experimental groups received epicatechin in injectable form in doses $10 \mu \mathrm{g} \cdot \mathrm{kg}^{-1}$ in E1, $100 \mu \mathrm{g} \cdot \mathrm{kg}^{-1}$ in E2 and 1000 $\mu \mathrm{g} . \mathrm{kg}^{-1}$ in $\mathrm{E} 3$ for four weeks three times a week. At the end of experiment the blood was collected, selected antioxidant parameters (catalase - CAT, glutathione peroxidase - GPx, superoxide dismutase - SOD, uric acid - UA, bilirubine and albumin) were analysed by Genesys 10 spectrophotometer (Thermo Fisher Scientific Inc., Waltham, MA, USA) using the commercial kits. The present study has shown that the activity of SOD and activity of CAT was lower in all experimental groups when compare with the control group after four week exposure of epicatechin but without significant differences. Activity of GPx was higher in all experimental groups against the control group but also without significant differences. The highest concentration of UA in rabbit serum was observed in E1 experimental group with the lowest concentration of epicatechin when compared with the other experimental groups and with the control group but without significant differences. Concentration of bilirubine in rabbit serum after administration of epicatechin was insignificantly lowest in all experimental groups in comparison with the control group. Content of albumin was not affected by epicatechin. Further research needs to be focused on the generation of data dealing with antioxidant effects, in both human and animals.
\end{abstract}

Keywords: Antioxidant parameters, epicatechin, rabbit blood

\section{INTRODUCTION}

Oxidative damage to important biomolecules, including lipoprotein and DNA, is considered to accompany arteriosclerosis, carcinogenesis and acceleration of aging. This oxidative damage may be inhibited by daily intake of antioxidants (Ames, 1983). Natural sources for these compounds include fruits and vegetables such as grapes, raspberries, onions, tomatoes, red wine, tea, etc. (Kähkönen $\boldsymbol{e t}$ al., 1999). Their antioxidant properties are well defined by in vitro experiments (Rice-Evans et al., 1997; Nastume et al., 2004) and there are indications of their beneficial effects in the prevention of diseases, when they are part of the diet (Ortega, 2006). The antioxidant activity of dietary polyphenols is considered to be much greater than that of the essential vitamins, therefore contributing significantly to the health benefits of fruit (Tsao and Yang, 2003). The term antioxidant refers to free radical scavengers, inhibitor of lipid peroxidation and chelating agents (Lee et al., 2003). Epicatechin is a member of a group of polyphenolic compounds collectively known as catechins, belonging to flavonoid family. It is a constituent of grape seeds and grape skin tannins, tea tannins, cocoa flavonoids, cola nuts, strawberries and red wine (Quine and Raghu, 2005). Several epidemiological investigations and dietary interventions in humans using flavanol-containing foods indicate an inverse relationship between flavanol intake and the improvement of immune responses and antioxidant defense system (Sies et al., 2005). Specifically, in the last 10 years, a strong interest has been raised in the use of flavonoids and their derivatives for the therapeutic use, such as anti-inflammatory, anticancer, anti-ischemic, and antithrombotic components. Besides from presenting potent antioxidant properties in vitro, these compounds have also the ability to modulate the activity of the antioxidant defense enzymes such as superoxide dismutase (SOD), glutathione peroxidase (GPx), and catalase (CAT) (Chan et al., 2002; Ying $\boldsymbol{e}$ al., 2004; Li et al., 2007). SOD converts superoxide to hydrogen peroxide, which is then removed by GPx and CAT (Afonso et al., 2007). Against oxidative stress, the human organism deploys an interactive network of antioxidants. The first line of defense consists of preventive antioxidants, which suppress the formation of free radicals (e.g. antioxidant enzymes). The another line of defense consists of antioxidants that scavenge free radicals by suppressing chain initiation and/or stopping multiple chain reactions (e.g. uric acid, albumin, bilirubin) (Simos et al, 2012). Uric acid is a powerful antioxidant and is a scavenger of singlet oxygen and radicals (Ames et al., 1981). Bilirubin is a bile pigment and has an important role as an antioxidant. Bilirubin, through a hydrogen donation mechanism, participates as a scavenger of secondary oxidants formed in the oxidative process and thereby might alleviate oxidant stress in the blood. It might primarily protect cells against lipid peroxidation (Sedlak and Snyder, 2004). Albumin may represent the major and predominant circulating antioxidant in plasma (Cha and Kim, 1996). Albumin represents the quantitatively most important source of thiol in plasma, and this circulating store may be altered in situations where antioxidants become limiting, resulting in changes in the redox status (Durand et al., 1997). However, little is known about the molecular mechanisms of flavanol-mediated bioactivities in both humans and animals. The aim of present study was to analyse selected antioxidant parameters in blood of rabbits after epicatechin administration during four weeks.

\section{MATERIAL AND METHODS}

\section{Animals}

Adult female rabbits $(n=16)$, maternal albinotic line (crossbreed Newzealand white, Buskat rabbit, French silver) and paternal acromalictic line (crossbreed Nitra's rabbit, Californian rabbit, Big light silver) were used in experiment. Rabbits were healthy and their condition was judged as good at the commencement of the experiment. Water was available at any time from automatic drinking troughs. Groups of adult animals were balanced for age (150 days) and body weight $(4 \pm 0.5 \mathrm{~kg})$ at the beginning of the experiment. Adult

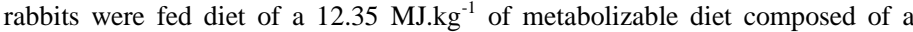
pelleted concentrate (table 1). 
Animals were divided into four groups: control group (C) and experimental groups (E1 - E3). Experimental groups received epicatechin in injectable form at $10 \mu \mathrm{g} \cdot \mathrm{kg}^{-1}$ in E1, $100 \mu \mathrm{g} \cdot \mathrm{kg}^{-1}$ in E2 and $1000 \mu \mathrm{g} . \mathrm{kg}^{-1}$ in $\mathrm{E} 3$ for 4 weeks three times a week.

In this animal study, institutional and national guidelines for the care and use of animals were followed, and all experimental procedures involving animals were approved by ethical committee.

\section{Blood sampling and analyses}

Blood samples from vena auricularis were taken from all animals by macromethod after four weeks of epicatechin administration. Catalase - CAT, glutathione peroxidase - GPx, superoxide dismutase - SOD, uric acid - UA, bilirubine and albumin were measured using the Genesys 10 spectrophotometer (Thermo Fisher Scientific Inc., Waltham, MA, USA). Activity of CAT was performed according to Beers and Sizer (1952) monitoring the decrease of $\mathrm{H}_{2} \mathrm{O}_{2}$ at $240 \mathrm{~nm}$ in blood plasma. The calculation of CAT activity was based on the rate of decomposition of $\mathrm{H}_{2} \mathrm{O}_{2}$, which was proportional to the reduction of the absorbance during 1 min. (Tvrda et al., 2013). SOD and GPx activity and UA content were analyzed with the RANDOX assay kits (Randox Laboratories, Crumlin, UK) according to the manufacturer's instructions. Albumin concentration was measured using the ALB BioLa Test (PLIVA-Lachema, Brno, Czech Republic) commercial kit. Concentration of bilirubine was measured by photometric test using the commercial kit DiaSys (Diagnostic Systems GmbH, Germany).

Table 1 Chemical composition (g.kg $\left.{ }^{-1}\right)$ of the experimental diet.

\begin{tabular}{lc}
\hline Component & Content $\left(\mathrm{g} \cdot \mathrm{kg}^{-1}\right)$ \\
\hline Dry matter & 926.26 \\
Crude protein & 192.06 \\
Fat & 36.08 \\
Fibre & 135.79 \\
Non-nitrogen compounds & 483.56 \\
Ash & 78.78 \\
Organic matter & 847.49 \\
Calcium & 9.73 \\
Phosphorus & 6.84 \\
Magnesium & 2.77 \\
Sodium & 1.81 \\
Potassium & 10.94 \\
Metabolizable energy & $12.35 \mathrm{MJ}^{\mathrm{kg}} \mathrm{kg}^{-1}$ \\
\hline
\end{tabular}

\section{Statistical analyses}

The data used for statistical analyses represent means of values obtained in blood collection. To compare the results, one-way ANOVA test was applied to calculate basic statistic characteristics and to determine significant differences among the experimental and control groups. Statistical software SIGMA PLOT 12.0 (Jandel, Corte Madera, CA, USA) was used. Differences were compared for statistical significance at the level $P<0.05$.

\section{RESULTS AND DISCUSSION}

Polyphenols have various important biological properties in both plants and animals that can be divided into two main categories, with antioxidant and nonantioxidant function (Shay et al, 2015). Regarding antioxidant action, it is noteworthy that polyphenols are the most abundant antioxidants in the diet with a total daily intake as high as 1 gram, exceeding the intake of vitamin $\mathrm{C}$ by about 10 -fold and that of vitamin E and carotenoids by about 100-fold (Scalbert $\boldsymbol{e t}$ al, 2008). In our study, we used 10,100 and $1000 \mu \mathrm{g}$ per $\mathrm{kg}$ of body weight of epicatechin and analysed selected antioxidant parameters in rabbit blood. The results are presented in Table (2). Epicatechin in these concentrations had no significant influence on the observed parameters $(P>0.05)$. The present study has shown that the activity of SOD and activity of CAT was lower in al experimental groups when compare with the control group after four week exposure of epicatechin but without significant differences $(\mathrm{P}>0.05)$. Activity of GPx was higher in all experimental groups against the control group but also without significant differences $(P>0.05)$. It has been reported that catechins has a strong anti-superoxide formation effect, by scavenging superoxide anion (Ho et al. 1999; Reddy et al. 2004). Catalase, present in phagocytes is effective only at high concentration of hydrogen peroxide (Halliwell and Gutteridge 1989). Base on this, we can suppose that in this case if there has been an increase of oxidative stress, epicatechin was able to scavenge reactive oxygen species and concentrations of antioxidant enzymes in blood did not rise. In the other hand, the decrease in the activity of SOD may be attributed to the saturation of SOD during the process of converting $\mathrm{O}_{2} \bullet$ to $\mathrm{H}_{2} \mathrm{O}_{2}$ (Eraslan et al., 2007). The major function of GPx, which uses glutathione (GSH) as a substrate, is to reduce soluble $\mathrm{H}_{2} \mathrm{O}_{2}$ and alkyl peroxides (Bebe and Panemangalore, 2003). GPx also can decompose $\mathrm{H}_{2} \mathrm{O}_{2}$ to water (Tian et al., 1998). It may be reason why the activity of GPx was slightly increased.

\begin{tabular}{|c|c|c|c|c|c|c|}
\hline Parameter & SOD & CAT & GPx & UA & Bilirubine & Albumin \\
\hline Group & {$\left[\mathrm{U} \cdot \mathrm{ml}^{-1}\right]$} & {$\left[\mathrm{U} \mathrm{mg}\right.$ protein $\left.^{-1}\right]$} & {$\left[\mathrm{U} .1^{-1}\right]$} & {$\left[\mu \mathrm{mol} .1^{-1}\right]$} & {$\left[\mu \mathrm{mol}^{-1} \mathrm{I}^{-1}\right]$} & {$\left[\mathrm{g} \cdot \mathrm{l}^{-1}\right]$} \\
\hline $\mathrm{C}$ & $94.75 \pm 6.24$ & $0.35 \pm 0.12$ & $1205.02 \pm 189.49$ & $82.78 \pm 11.79$ & $1.85 \pm 0.48$ & $35.56 \pm 1.23$ \\
\hline E1 & $86.25 \pm 7.81$ & $0.28 \pm 0.06$ & $1447.92 \pm 301.20$ & $109.33 \pm 16.46$ & $3.13 \pm 0.97$ & $33.58 \pm 0.53$ \\
\hline E2 & $89.50 \pm 4.20$ & $0.22 \pm 0.07$ & $1302.79 \pm 41.00$ & $76.53 \pm 13.53$ & $2.82 \pm 0.34$ & $33.06 \pm 1.58$ \\
\hline E3 & $90.00 \pm 3.60$ & $0.28 \pm 0.07$ & $1235.51 \pm 85.19$ & $78.49 \pm 9.66$ & $2.2 \pm 0.70$ & $36.37 \pm 0.38$ \\
\hline
\end{tabular}

Uric acid (UA) is involved in a complex reaction with several oxidants and may have some protective effects under certain conditions. On the other hand, uric acid cannot scavenge all radicals, with superoxide as an example. Uric acid is an antioxidant only in the hydrophilic

environment, which is probably a major limitation of the antioxidant function of uric acid (Sautin and Johnson, 2008). In our study, the highest concentration of UA in rabbit serum was observed in E1 experimental group with the lowest concentration of epicatechin (10 $\left.\mu \mathrm{g} \cdot \mathrm{kg}^{-1}\right)$ when compared with the other experimental groups and with the control group but without significant differences $(\mathrm{P}>0.05)$. Administration of $(+)$ - catechin hydrate increased levels of uric acid which may be one of the reasons for protection against diet induced oxidative stress (Mehra et al., 2007). Administration of EGCG in healthy human individuals increased plasma antioxidant activity which was not due to changes in EGCG concentration but due to changes in plasma urate concentrations, which might have interfered with the effect of EGCG to promote antioxidant activity (Susanne et al., 2005). In the other hand, high plasma uric acid (UA) is a prerequisite for gout and is also associated with the Metabolic Syndrome and risk factors for cardiovascular diseases (Kim et al., 2009). In our study, the concentration of UA in blood serum of rabbits was lower in groups with higher concentration of epicatechin $\left(100 \mu \mathrm{g} . \mathrm{kg}^{-1}\right.$ in E2 and $1000 \mu \mathrm{g} \cdot \mathrm{kg}^{-1}$ in E3 group) against the control group however without significant differences $(\mathrm{P}>$ 0.05 ). There is still no consensus if UA is a protective or a risk factor, however, it seems that the quantity and the duration of the concentration of the uric acid in the blood is essential for this answer (Oliveira and Burini, 2012).

Bilirubin has been reported as a member of the antioxidant family and is even known to have toxic effects at high concentration. The combined evidence from animal and human studies indicates that bilirubin is a major physiologic cytoprotectant and might alleviate oxidative stress in the blood (Sedlak and Synder, 2004). Our results showed that concentration of bilirubine in rabbit serum after administration of epicatechin was insignificantly $(P>0.05)$ lowest in all experimental groups in comparison with the control group. In the study of authors Petruška et al. (2013) that long-term application of quercetin caused the increase of concentration of bilirubine in rabbit serum. Findings of Loprinzi and Mahoney (2015) suggested an association between flavonoid-rich fruit and vegetable consumption and bilirubin levels. If confirmed by prospective and experimental studies, then regular consumption of flavonoid-rich fruits and vegetables should be promoted to increase levels of bilirubin.

Albumin represents a very abundant and important circulating antioxidan (Roche et al., 2008). Study of Bourdon et al. (1999) confirmed and extended the idea that serum albumin is an important protein that presents direct protective 
effects. In our study, concentration of serum albumin was very similar among all groups. Thus, we can say that any used concentration of epicatechin have effect on this parameter in rabbits. In study of Petruška et al. (2013) they observed slight decrease in the content of serum albumin in quercetin groups vs. control group of rabbits. Several lines of evidence strongly suggest that a reduced serum albumin concentration, although within the normal range, is associated with mortality risk (Bourdon et al., 1999).

\section{CONCLUSION}

Selected antioxidant parameters in rabbit blood after four weeks exposure of epicatechin in this study were assessed. Four weeks of intramuscular application of epicatechin at various doses resulted in slight changes in selected antioxidant parameters of rabbits without significant differences. Catechins when compared with other classes of flavonoids are found to be very active in reducing the amount of strand breakage and residual base damage by mechanism other than directly scavenging of hydroxyl radicals before they react with DNA. To determine whether epicatechin act as effective antioxidant in vivo, future studies in animals and humans should employ sensitive and specific biomarkers of oxidative damage to DNA, proteins and lipids.

Acknowledgments: This work was financially supported by VEGA scientific grant $1 / 0760 / 15$. This work was co-funded by European Community under project no 26220220180: Building Research Centre "AgroBioTech".

\section{REFERENCES}

Alfonso, V., Champy, R., Mitrovic, D., Collin, P., Lomri, A. (2007). Reactive oxygen species and superoxide dismutases: role in joint diseases. Joint Bone Spine, 74, (4), 324-329. http://dx.doi.org/10.1016/j.jbspin.2007.02.002

Ames B.N. (1983). Dietary carcinogens and anticarcinogens. Science, 221 (4617), 1256-1264. http://dx.doi.org/10.1126/science.6351251

Ames, B.N., Cathcart, R., Schwiers, E., Hochstein, P. (1981). Uric acid provides an antioxidant defence in humans against oxidant- and radical-caused aging and cancer: A hypothesis. Proceedings of the National Academy of Sciences, 78 (11), 6858-6862. http://dx.doi.org/10.1073/pnas.78.11.6858

Bebe, F.N., Panemangalore, M. (2003). . Exposure to low doses of endosulfan and chlorpyrifos modifies endogenous antioxidants in tissues of rats. Journal of Environmental Science and Health, 38 (3), 349-363. http://dx.doi.org/10.1016/j.pestbp.2006.08.010

Beers, R.F.Jr., Sizer, I.W. (1952). A spectrophotometricmethod formeasuring the breakdown of hydrogen peroxide by catalase.The Journal of Bioogical Chemistry, 195 (1), 133-140.

Bourdon, E., Loreau, N., Blache, D. (1999). Glucose and free radicals impair the antioxidant properties of serum albumin. FASEB Journal, 13, (2), 233-244. by tea polyphenols. Biomedical and nvironmental Sciences, 17 (1), 33-39. Durand, P., Lussier-Caca, S., Blache, D. (1997). Acute methionine load-induced hyperhomocysteinemia enhances platelet aggregation, thromboxane biosynthesis and macrophage-derived tissue factor activity in rats. FASEB Journal, 11, (13), 1157-1168.

Eraslan, G., Saygi, S., Essiz, A., Aksoy, A., Gul, H., Macit, E. (2007). Evaluation of aspect of some oxidative stress parameters using vitamin E, proanthocyanidin and Nacetylcysteine against exposure to cyfluthrin in mice. Pesticide

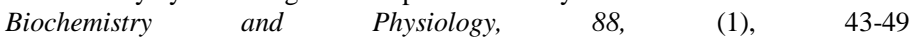
http://dx.doi.org/10.1016/j.pestbp.2006.08.010

Halliwell, B., Gutteridge, M.C.J. (1989). Free Radicals in Biology and Medicine second ed. Oxford University press, Oxford.

Ho, K.Y., Huang, J.S., Tsal, C.C., Lin, T.C., Hsu, Y.F., Lin, C.C. (1999) Antioxidant activity of Tannin components from Vaccinium Vitis-idaea L. Journal of Pharmacy and Pharmacology, 51, (9), 1075-1078. http://dx.doi.org/10.1211/0022357991773410

Cha, M.K., Kim, I.H. (1996). Glutathione-linked thiol peroxidase activity of human serum albumin: a possible antioxidant role of serum albumin in blood plasma. Biochemical and Biophysical Research Communications, 222, (2) 619625. DOI: http://dx.doi.org/10.1006/bbrc.1996.1234

Chan, P., Cheng, J.T., Tsai, J.C., Lien, G.S., Chen, F.C., Kao, P.F. (2002). Effect of catechin on the activity and gene expression of superoxide dismutase in cultured rat brain astrocytes. Neuroscience Letters, 328 (3), 281-284 http://dx.doi.org/10.1016/s0304-3940(02)00552-9

Kähkönen M.P., Hopia A.I., Vuorela H.J., Rauha J.P., Pihlaja K., Kujala T.S (1999). Antioxidant activity of plant extracts containing phenolic compounds. Journal of Agricultural and Food Chemistry, 47 (10), 3954-362. http://dx.doi.org/10.1021/jf9901461

Kim S.Y., Guevara J.P., Kim K.M., Choi H.K., Heitjan D.F., Albert D.A. (2009) Hyperuricemia and risk of stroke: a systematic review and meta-analysis. Arthritis an Rheumatism, 61, (2), 885-892. http://dx.doi.org/10.1002/art.24612 Lee, S.R., Im, K.J., Suh, I.H., Jung, J.G. (2003). Protective effect of green tea polyphenol (-) epigallocatechin gallate and other antioxidants on lipid peroxidation in gerbil brain homogenates. Phytotherapy research, 17 (3), 206209. http://dx.doi.org/10.1002/ptr.1090
Li Y.M., Chan H.Y.E., Huang Y., Chen Z.Y. (2007). Green tea catechins upregulate superoxide dismutase and catalase in fruit flies. Molecular Nutrition and Food Research, 51 (5), 546-554. http://dx.doi.org/10.1002/mnfr.200600238 Loprinzi, P.D., Mahoney, S.E. (2015). Association Between Flavonoid-Rich Fruit and Vegetable Consumption and Total Serum Bilirubin. Angiology, 66, (3), 286290. http://dx.doi.org/10.1177/0003319714537111

Mehra, P., Koul, A., Bansal, D.D. (2013). Studies on Antioxidant Role of (+)Catechin Hydrate in High Sucrose High Fat Diet Induced Oxidative Stress. American Journal ao Biomedical Sciences, 5, (2), 161-170 http://dx.doi.org/10.5099/aj130200161

Natsume M., Osakabe N., Yasuda A., Baba S., Tokunaga T., Kondo K. (2004). In vitro antioxidative activity of (2)-epicatechin glucuronide metabolites present in human and rat plasma. Free Radical Research, 38 (12), 1341-1348. DOI: http://dx.doi.org/10.1080/10715760400022087

Oliviera, E.P., Burini, R.C. (2012). High plasma uric acid concentration: causes and consequences. Diabetology and Metabolic Syndrome, 4, (1), 12 http://dx.doi.org/10.1186/1758-5996-4-12

Ortega, R.M. (2006). Importance of functional foods in the mediterranean diet. $\begin{array}{llll}\text { Public Health Nutrition, } 9 & \text { (8A), } & 1136-1140 .\end{array}$ http://dx.doi.org/10.1017/s1368980007668530

Petruska, P., Zbynovska, K., Kalafova, A, Kolesarova, A., Capcarova, M. (2013). Effect of chronic application of quercetin and acute dose of T-2 toxin on content of serum bilirubin and albumins of rabbits. Animal welfare, ethology and housing systems, 9, (3), 583-588.

Quine, S.Q., Raghu, P.S. (2005). Effects of (-)-epicatechin, a flavonoid on lipid peroxidation and antioxidants in streptozotocin-induced diabetic liver, kidney and heart. Pharmacological reports, 57 (5), 610-615.

Reddy, Y.N., Murthy, S.V., Krishna, D.R., Prabhakar, M.C. (2004). Role of free radicals and antioxidants in tuberculosis patients. Indian Journal of Tuberculosis 51, 213-218.

Rice-Evans C.A., Miller N.J., Paganga G. (1997). Antioxidant properties of phenolic compounds. Trends in Plant Science, 2 (4), 152-159. http://dx.doi.org/10.1016/S1360-1385(97)01018-2

Roche, M. Rondeau, P., Singh, N.R., Tarnus, E., Bourdon, E. (2008). The antioxidant properties of serum albumin. FEBS Letters, 582, (13), 1783-1787. http://dx.doi.org/10.1016/j.febslet.2008.04.057

Sahy, J., Elbaz, H.A., Lee, I., Zielske, S.P., Malek, M.H., Huttemann, M. (2015). Molecular Mechanisms and Therapeutic Effects of (-)-Epicatechin and Other Polyphenols in Cancer, Inflammation, Diabetes, and Neurodegeneration. Oxidative Medicine and Cellular Longevity, 2015, 1-13. http://dx.doi.org/10.1155/2015/181260

Scalbert, A., Johnson, I.T., Saltmarsh, M. (2005)."Polyphenols: antioxidants and beyond,"The American Journal of Clinical Nutrition, 81, (1), 215S-217S.

Sedlak, T.W., Snyder, S.H. (2004). Bilirubin benefits: cellular protection by a biliverdin reductase antioxidant cycle. Pediatrics. 113, (6) 1776-1782 http://dx.doi.org/10.1542/peds.113.6.1776

Sies, H., Schewe, T., Heiss, C., Kelm, M. (2005). Cocoa polyphenols and inflammatory mediators. The American Journal of Clinical Nutrition, 81(1), 304S-312S.

Simos, Y.V., Verginadis, I.I., Toliopoulos, I.K., Velalopoulou, A.P., Karagounis, I.V., Karkabounas, S.C., Evangelou, A.M. (2012). Effects of catechin and epicatechin on superoxide dismutase and glutathione peroxidase activity, in vivo.
Redox
Report,
17
$(5)$
181

186. http://dx.doi.org/10.1179/1351000212y.0000000020

Susanne, M.H., Yantao, N., Nicolas, H.L., Hara, Y., Thamas, G.D., Minutte, R., Carpenter, C.L., Wang, H., David, H. (2005). Bioavailability and antioxidant effect of epigallocatechin gallate administered in purified form versus green tea extract in healthy individuals, The Journal of Nutritional Biochemistry, 16, (10), 610-616. http://dx.doi.org/10.1016/j.jnutbio.2005.03.003

Tian, L., Cai, Q., Wei, H. (1998). Alterations of antioxidant enzymes and oxidative damage to macromolecules in different organs of rats during aging. Free radical Biology and Medicine, 24, (9), 1477-1484. http://dx.doi.org/10.1016/s0891-5849(98)00025-2

Tsao, R., Yang, R. (2003). Optimization of a new mobile phase to know the complex and real polyphenolic composition: towards a total phenolic index using highperformance liquid chromatography. Journal of Chromatography A,1018 (1), 29-40. http://dx.doi.org/10.1016/j.chroma.2003.08.034

Tvrda, E., Knazicka, Z., Lukacova, J., Schneidgenova, M., Goc, Z., Gren, A., Szabo, C., Massanyi, P., Lukac, N. N., (2013). The impact of lead and cadmium on selected motility, prooxidant and antioxidant parameters of bovineseminal plasma and spermatozoa. Journal of Environmental Science and Health, Part A, 48, (10), 1292-1300. http://dx.doi.org/10.1080/10934529.2013.777243

Ying C.J., Sun X.F., Zhang S.L., Zhang X.P., Mao L.M., Zuo X.Z. (2004). ROS related enzyme expressions in endothelial cells regulated

Yuri, Y., Sautin, Y., Johnson, R.J. (2008). Uric acid: The Oxidant-Antioxidant Paradox. Nucleosides, Nucleotides and Nucleic Acids, 27, (6-7), 608-619. http://dx.doi.org/10.1080/15257770802138558 